\title{
Translation Quality of Subtitle Text in Greta's Movie
}

\author{
Zahara Marhamah ${ }^{1, *}$ Anni Holila ${ }^{2}$ Zainuddin $^{3}$ \\ ${ }^{1}$ English Applied Linguistic Study Program, Post-Graduate, State University of Medan \\ ${ }^{2}$ State University of Medan \\ ${ }^{3}$ State University of Medan \\ *Corresponding author. Email: zahara.zms73@gmail.com
}

\begin{abstract}
The research was aimed to finding out "Translation Quality of Subtitle Text in Greta's Movie". The purpose of this study is to analyze Translation Quality Subtitle Text in Greta's Movie from English to Indonesian based on three aspects of translation quality, namely accuracy, acceptability and readibility. The methodology used in this research is descriptive qualitative method. The data is analyzed based on the assessment model translation quality (accuracy aspect, acceptability aspect, and readability aspect). Based on the results of the analysis in this study, 300 data were obtained with an assessment score of 1 to 3. From the three aspects of translation quality, in this study the average assessment of the readability aspect was 2.58 the accuracy aspect is 2.38 , and the acceptability aspect is 1.93 . Based on the results of the average score of the quality assessment of subtitle text translation in Greta's Movie, it was found that the accuracy, acceptability, and readability were high. So it can be concluded that the translation quality of Subtitle Text in Greta's Movie is accurate, acceptable and readable. Over all subtitle text translation have good quality.
\end{abstract}

Keywords: translation quality, subtitle translation, accuracy, acceptability, readability.

\section{INTRODUCTION}

The translation attempts to convey a message or a specific purpose to the language being addressed because of limitations or the in ability to respond to something from a language. There are many languages in this world, and it is almost impossible for everyone to master all of them, so translation is a solution to existing problems.

According to Newmark (1988), the translator conveys the author's intent by translating the text's meaning into other languages. Translation is the process of converting the source language (SL) to the target language (TL), with numerous stages that result in translations that fulfill the requirements. The translation is the target text that the translator creates as a result of his or her understanding of the source text. However, as the twentieth century progressed, numerous specialists created definitions with divergent inclinations.

Nababan (2003) states that there are two factors that the translator must consider. The first factor is linguistic factors which include words, phrases, clauses and sentences. The second is nonlinguistic factors which include cultural knowledge about source culture and target language. The translator is critical in achieving the target language because the translation must transfer ideas, thoughts, and messages from the source language (SL) to the target language (TL) in the most logical and natural manner possible.
The film is one of the electronic media in the form of audiovisual that is used to reflect reality as well as convey information that can be consumed in depth. Allen and Gomery (1985), in their book entitled Film History Theory and Practice, the film is a depiction of the social conditions of a society, it is manifested in the form of images and sounds, while the themes and stories originate from a description of the condition of the community itself.

A translator may choose to utilize subtitles when translating a film. Subtitles allow viewers to hear the original language, while speech is displayed at the bottom of the screen. When creating subtitles, the translator should strive to make them as unobtrusive as possible without diverting the viewer's focus. According to Mera in Szarkowska (2005), subtitles need a higher level of attention from viewers than dubbed films do since they transform film from an audiovisual medium to a more literate media. Additionally, the subtitle should correspond to the dialogue spoken by the characters; this ensures that the audience is not confused about the story.

Greta's Movie was chosen for analysis because it depicts a kindhearted girl named Frences risking her life in Manhattan (New York) in order to return a suitcase left on the subway to an elderly woman named Greta. The film Greta by Neil Jordan encourages us not to trust new people even though they are old easily. Friendly should 
be, but do not let it be easy to connect with new people because they can't be the friends we are looking for and because good intentions do not always end well. This story is suitable to be analyzed according to students who live in cities far from home and their parents. The quality of translations must be tested for accuracy, so viewers can take lessons from each plot.

\section{REVIEW OF LITERATURE}

According to Larson (1984), translation is fundamentally a question of form alterations. The translation process will take two distinct shapes. They are source language (the form from which the translation is made) and target language (the form into which the translation is to be made). This refers to the process of translating, in which a translator converts the source material into the target language's form.

Many experts define translation. Nababan (1999) defines translation as simply the process of transferring messages between languages. He clears the line between translation and interpretation. Translation concerns the message in the written text. In contrast, interpretation is concerned with the linguistic communication. In other words, Bell (1991) defines translation as "the process of replacing a text's representation in one language with an equivalent text in another." That is, a translation is a text written to assist people in comprehending a text they wish to learn in a language they do not understand. Even when the source language's form is altered in the target language, the meaning must remain consistent, as it is the most critical aspect of translation. A perfect translation keeps the source text's meaning in the target language's natural form.

\subsection{Translation Quality Assessment}

There are already a wide range of Translation Quality Assessment (TQA) systems available to us. The issue is not whether we can quantify quality, but rather how we can quantify it (Nerudova, 2012). Nonetheless, some authorities establish distinct criteria for determining whether a translation is acceptable or unacceptable.

There are many ways that translators can assess the quality of translations. Larson (1998) mentions three categories that need to be noticed to measure the quality of translation e.i. Accuracy, clarity, and naturalness. Thus, the quality of translation is assessed by how accurate, clear, and natural the result of the translation. Larson explained that comparing the translation product with the source text can be applied to assess the quality of a translation. This comparison can be conducted by fourmethods, i.e.,1) compare the translation result with the source text at several points, 2) after the comparison is complete, do it one more time carefully, 3) when checking for equivalence of information context, make sure that all the information is included, nothing omit or different, 4) Finally makethe last comparison to make sure that all the information is included.

\subsubsection{Accuracy in Translation}

Accuracy is a term used to describe the degree to which a translation conveys the same idea as the original. It is a transfer of meaning from the source language to the target language that occurs without addition or subtraction of meaning. Typically, this is referred to as the preservation of SL's information content in TL. When translating a text, the translator should also consider the familiar language pattern used by the intended audience. Accurate signifies that the meaning of the The source language is conveyed accurately in the target language text; no meaning distortion occurs. Less Accurate indicates that the meaning of the source language is not accurately conveyed in the target language. There are some ambiguities in the meaning. The source language indicates inaccuracy, implying that it is not accurately translated into the target language. It is omitted or omitted entirely (Nababan, 2004).

\subsubsection{Acceptability in Translation}

Acceptability is related to the concept of naturalness and the reader's emotional response-the translator's success in producing a translation that is as natural as the original text is determined by acceptability. Acceptability, according to (Williams, 2004), is the quality of translation in relation to the target language's applicable standards. Acceptability of implementation demonstrates that the translator adheres to the target culture's norms. The translator violates target language conventions when he employs a structure of language that is rarely used and serves a different purpose. As a result, it may impair the target reader's ability to comprehend the translation text. Acceptability refers to the translation's language naturalness and compatibility with the target language. Acceptable translations should satisfy the requirement of reading as an original written in the target language, rather than reading as the original. When readers desire to read an original text written in the target language, a translation is acceptable. That is, the target text should sound natural.

\subsubsection{Readability in Translation}

The average sentence length, the number of new words, and the grammatical complexity of the language used all contribute to readability. There are several readability factors that contribute to the difficulty of the text being understood by the reader, particularly nonbilingual readers. These factors include the use of ambiguous words and sentences, the use of incomplete sentences, punctuation, grammatical aspects, and sentence construction, among others. The readability analysis is used to ensure that the target readers can grasp the concept conveyed by the word in the target language, and it also serves as a readability criterion for the strategy's accuracy.

\section{RESEARCH METHOD}

The method used in this research was descriptive qualitative. Moleong stated (2005), 
"Qualitative research is the research that's meantto understand the phenomenon about what is the subject research undergone by using the natural method. On the other hand, qualitative research was chosen to determine how accurate, acceptable, and readable the subtitles text in Greta's Movie .In this research, the data taken from subtitle text in Greta's Movie. The data be analyzed 300 data.

\section{RESULT}

The research results will be described, namely quality analysis in subtitles text of the movie Greta's movie is divided into several scenes to facilitate data collection, where the scenes are to make it easier for raters to judge so that more focused and focused on each scene. Amount of data studied as much as 300 data in the form of subtitles text of the Greta's Movie. The data was analyzed based on the translation quality assessment model (Nababan, 2012:50) was divided into three aspect: accuracy, acceptability, and readability.

Based on the result of the data analysis, the findinBased on Nababan's theory there were three aspect of translation quality namely accuracy, acceptability and readability. The aspects of translation quality were used in the different frequency. They were accuracy aspects which consists of accurate $(84.33 \%)$, less accurate $(14 \%)$, inaccurate $(1.3 \%)$. Nababan's theory said that accuracy aspects divided into three, namely accurate, less accurate and inaccurate. From the Greta's Movie the researcher found the text from the source language translated into target language. While, the acceptability aspects which consist of acceptable $(83,66 \%)$, less acceptable (14\%) and unacceptable $(2,3 \%)$. The last one, readability aspects which consist of readable $(87.33 \%)$, less readable $(11.33 \%)$ and unreadable $(1.3 \%)$. Thus, the dominant aspects that found from Greta's Movie areaccurate, acceptable and readable. It means, Greta's Movie is included into good quality of translation.

There are three factors that determined translation quality in Greta's Movie namely 1) transfer of messages, in this process, the translator should be understood the meaning of the text or structure from the source language. For the next step, the translator turned its contents, meaning and messages contained in the source language to the target language. And in this stage the translator is required to find the matching words are appropriate for use in the target language. The transfer of the message from this novel is middle good quality in transferring the meaning. 2) the accuracy of the message, in transfer the message, not only required the accurate of the text but also accuracy should be accompanied by clarity meaning. A translation will not have a value if the reader is not able to understand the explanation contained in it because one of the indicators of the quality of a translation is the understanding of the reader. The accuracy of the message in this novel is middle good quality in accurate the meaning. 3) the nature language of the translation, In this process, the quality of a translation is not only determined by the accuracy in the use of diction or the ease of the reader in understanding the content of the translated text, but the quality of the translation work is also influenced by the ability of the translator in the bring back the situation that exists in the source text into the target. Product translation result should not violate norms, structures and culture that occurred among the readers of the text object. Therefore, a translator should use a grammar and language style is also applicable in the target language but in accordance with the nature target language.

Based on analysis of the questionnaire to the raters, the researcher found out that the aspects of translation quality in Greta's Movie are accurate with the average points around 2.53 , acceptable with the average points around 2.51 and readable with the average points around 2.64 .

In translating Greta's Movie, there are three realization that applied by the translator namely (1) The first realizations are the mistranslation, omission, addition and untranslated which related to the accuracy. In this novel, there so many omission or addition which found by the researcher from source language to the target language. (2) Second realization is relevancy and naturalness of the text. The naturalness is needed in translation quality, whether the words, phrases, clauses and sentences of the source text are appropriate or inappropriate with the target language principles. (3) Third realization is the used of diction and sentence forms. Diction is used to emphasize the manner of writing on the text. While, the sentence forms which related to ambiguous sentences

\section{DISCUSSION}

After analyzing the data delivery, there were some findings found. From the data observation, the researcher can match the theory that relates to the study results. Nababan (2012) states that the assessment of a translation is made for the following reasons: 1) establishing a dialectical relationship in translation between theory and practice. 2) as criteria and standards for evaluating translators' competence.

In assessing translation quality, what is assessed is the result of the translation or the product, not the translation process. According to the journal Quality Assessment Model Development Translation by Nababan (2012), translation quality assessment must meet three aspects: aspects of accuracy, aspects of acceptability, and aspects of readability (Nababan, 2012). The purpose of this research is to develop a model for assessing the quality of translation. The researcher discovered that the highest score for translation quality was 2.66 in this study. Based on this score, the readability of the subtitles in Greta's Movie is considered to have good quality. Then the median value of the aspect of translation quality is 2.53. Based on this score, the accuracy of the subtitles in Greta's Movie Novel is considered to have good quality.

Furthermore, the lowest value from the aspect of translation quality is 2.51. Based on this score, the accuracy of Subtitle Text in Greta's Movie considered to have good quality. That is, the aspect of translation 
quality in film subtitles is accurate, acceptable, and readable.

The next result is the realization of the appraiser. In this study, after calculating the scores of both raters, the researcher found that the quality of the translation in Greta's Movie subtitles was accurate, acceptable, and readable. That is, the quality of the translation of Subtitle Text in Greta's Movie is a good translation. The same as the previous research proposed by Simanjuntak (2019) and Tino (2018). Both have the same findings that are accurate, acceptable, and readble. Simanjuntak researched idioms in abstraction, while Tino researched readability and acceptability accuracy.

\section{REFERENCES}

[1] Allen, R.C. and Gomery, D.1985. Film History, Theory and Practice. New York: Knopf.Bell, R. T. 1991. Translation and Translating: Theory and Practice. London: Longman.

[2] Catford, J.C. 1965. Linguistic Theory of Translation. Oxford: Oxford University Press.

[3] Emzir. 2014. Metodologi Penelitian Kualitatif: Analisis Data. Depok: Rajawali Pers.

[4] Halliday, M.A.K 1994. An Introduction to Functional Grammar Second Edition. London: Edward Arnold.

[5] Hoed, B. 2006. Penerjemahan dan Kebudayaan. Jakarta: Pustaka Jaya.

[6] Holmes, J. S. 1988. Translated Papers on Literary Translation and Translation Studies. Amsterdam: Odopi.

[7] Larson, M.L. 1998. Meaning-Based translation: A guide to cross language equivalence (2nd ed). Lanham: University Press of America.

[8] Moleong. 2005. Metodologi Penelitian Kualitatif. Bandung: PT Remaja Rosdakarya

[9] Munday, J. 2001. Introducing translation studies: Theory and application. New York: Routledge.

[10] Nababan, M. R. 2004. Translation Processes, Practices and Products of Professional Indonesian Translators. Unpublished Ph.D. Thesis. School of Linguistics and Applied Language Studies, Victoria Univ of Wellington, New Zealand.

[11] Nerudova, L. 2012. Quality of translation: approaches and a field survey. Thesis. Czech Republic: Masaryk University.

[12] Newmark, P. 1988. A Textbook of Translation. New York: Prentice Hall.
[9] A. Pnueli, In transition from global to modular temporal reasoning about programs, in: K.R. Apt (Ed.), Logics and Models of Concurrent Systems, Springer, Berlin, Heidelberg, 1984, pp. 123-144. DOI: https://doi.org/10.1007/978-3-642-82453-1_5

[10] B. Meyer, Applying "Design by Contract", Computer 25(10) (1992) 40-51. DOI: https://doi.org/10.1109/2.161279

[11] S. Bensalem, M. Bogza, A. Legay, T.H. Nguyen, J. Sifakis, R. Yan, Incremental component-based construction and verification using invariants, in: Proceedings of the Conference on Formal Methods in Computer Aided Design (FMCAD), IEEE Press, Piscataway, NJ, 2010, pp. 257-256.

[12] H. Barringer, C.S. Pasareanu, D. Giannakopolou, Proof rules for automated compositional verification through learning, in Proc. of the 2nd International Workshop on Specification and Verification of Component Based Systems, 2003.

[13] M.G. Bobaru, C.S. Pasareanu, D. Giannakopoulou, Automated assume-guarantee reasoning by abstraction refinement, in: A. Gupta, S. Malik (Eds.), Proceedings of the Computer Aided Verification, Springer, Berlin, Heidelberg, 2008, pp. 135-148. DOI: https://doi.org/10.1007/978-3-54070545-1_14 